doi:10.4149/neo_2012_011

\title{
Breast cancer patients with hypermethylation in the promoter of $B R C A 1$ gene exhibit favorable clinical status
}

\author{
M. E. KRASTEVA*, S. S. BOZHANOV, G. G. ANTOV, Z. I. GOSPODINOVA, S. G. ANGELOVA AND E. I. GEORGIEVA \\ Institute of Plant physiology and Genetics, Department of Molecular Genetics, Bulgarian Academy of Sciences, Acad. G. Bonchev Street, Bldg. \\ 21, 1113 Sofia, Bulgaria \\ *Correspondence: maria_krasteva@abv.bg
}

Received August 12, 2011 / Accepted August 23, 2011

\begin{abstract}
Promoter hypermethylation was shown to be involved in human cancerogenesis through silencing gene expression. Several studies were dedicated to explore the frequency and clinical significance of $B R C A 1$ hypermethylation in sporadic breast cancer to identify a specific molecular and clinico-pathological phenotype. However the available data are limited and rather too heterogeneous. In this study we investigated the level of methylation in the promoter region of BRCA1 and its correlation with clinico-pathological and molecular characteristics in a group of 135 Bulgarian patients. Methylation specific PCR was applied to determine methylation status of tumor samples. Clinical impact of BRCA1 hypermethylation was estimated using standard statistical methods including Fisher's exact and the Chi-squared tests, the Kaplan-Meier method, the univariate and multivariate Cox proportional hazards regression model. We found that hypermethylation was present in $17.04 \%$ of the cases $(23 / 135)$. Patients with hypermethylation in $B R C A 1$ displayed favorable clinical status as their tumors were smaller in size $(P=0.066)$, lacked $p 53$ gene mutations $(P=0.073)$ and were of lobular type $(P=0.046)$. The presence of hypermethylation was weakly associated with better overall survival $(P=0.2)$ with a hazard ratio of 0.47 (95\% CI $0.14-1.54, P=0.213$ ). Our study provides the first data on the $B R C A 1$ hypermethylation of Bulgarian patients and contributes to elucidation of its clinical significance in sporadic breast cancer.
\end{abstract}

Key words: Breast cancer, BRCA1, Hypermethylation, Clinicopathological characteristics, Overall survival

Breast cancer (BC) represents a major challenge to modern human oncology because of its high and constantly increasing frequency, and growing mortality and morbidity rate in women below the age of 45. Every year in Bulgaria, approximately 3600 women are diagnosed and about 1300 die of BC (1). The major risk factors are sex, age, family predisposition, as well as some reproductive and hormonal factors like early menarche and late menopause, late first childbirth, shorter breastfeeding period, use of oral contraceptives and hormone replacement therapy. Clinically BC is very heterogeneous, which is due to heterogeneity in disease mechanisms.

$\mathrm{BC}$ results from accumulation of genetic and epigenetic changes in tumor suppressor genes and proto-oncogenes. Some of these genes - p53, PIK3CA, CHEK2, ATM, HER2, are involved in the pathogenesis of different type of tumors. Others are specific only to breast/ovarian cancer - BRCA1 and BRCA2. A large number of studies demonstrate a correlation between the genetic/epigenetic status of BC related genes and clinicopathological characteristics of the patients. Such investigations could contribute to a more effective BC prevention and therapy, which will increase the survival rate and will significantly improve the quality of life of the patients. However, the results so far are contradictory and need further elucidation.

BRCA1 (BReast CAncer susceptibility gene 1) tumor suppressor gene maps to $17 \mathrm{q} 12-21$ (2). The gene is organized in 2 non-coding and 22 coding exons which span over $>80 \mathrm{~kb}$ of genomic DNA and encodes a 1,863 amino acids protein (3). Though its exact biological functions are not fully elucidated, it is known that BRCA1 is involved in maintaining genome integrity through participation in DNA damage repair (4), in the control of cell cycle checkpoints (5), in apoptosis (6), in preventing global DNA hypomethylation (7) and others. Mutations in BRCA1 were proved to be the main genetic event in hereditary type of breast cancer. Between 20 and $45 \%$ of hereditary cases are due to a germline mutation in the $B R C A 1$ gene. A BRCA1 mutation carrier has an early age at onset, and lifetime risk for breast cancer 50 to $85 \%$. However, no or limited somatic mutations in BRCA1 have been found in the 
more common sporadic form of the disease. Nevertheless, BRCA1 mRNA level was found to be reduced or absent in invasive sporadic breast tumors (8), thus assigning a role of $B R C A 1$ in sporadic breast cancer as well. This suggests that alternative mechanisms for loss of BRCA1 function could be involved, including DNA hypermethylation, dysregulation of transcriptional activators and/or repressors binding to the $B R C A 1$ locus or post-transcriptional processes.

The concept that gene silencing by promoter hypermethylation is a common mechanism for tumor initiation or progression is recently gaining more support. Most frequently hypermethylation occurs on 5'-methylcytosine residues of 5'-CpG-3' dinucleotides. Unlike mutations which are often randomly spread over the genome, the $\mathrm{CpG}$ sites are clustered into islands, typically found in the promoter regions of genes. Hypermethylation leads to structural changes in chromatin, which prevent the binding of transcriptional factors to DNA, thus decreasing the transcriptional activity of the genes. The maintenance of the normal methylation pattern is critical for the proper gene expression. As aberrant methylation leads to alteration in gene expression, it may serve as a basis for cancer development. Hypermethylation in a tumor suppressor gene was first described for the $R B$ gene in sporadic cases of retinoblastoma (9), followed by the VHL gene in clear cell renal carcinoma (10), the APC gene in colorectal carcinoma (11), the ATM gene in head and neck squamous cell carcinoma (12) and others. Hypermethylation of the $B R C A 1$ promoter in sporadic breast cancer samples was first detected by Dobrovic and Simpfendorfer (13). BRCA1 hypermethylation was found to be significantly more common in breast and ovarian tumors (14) indicating that it is breast/ovarian cancer specific (15). Hypermethylation of the BRCA1 promoter was proved to silence gene expression as it was associated with a decrease in the expression of $B R C A 1$ mRNA (16). The limited data available on the clinical impact of $B R C A 1$ hypermethylation failed thus far to outline a generally accepted clinico-pathological phenotype.

In this study we investigated the level of methylation in the promoter region of BRCA1 in BRCA1 mutation negative Bulgarian patients with sporadic breast cancer. Methylation status was determined using methylation specific PCR and clinical impact of $B R C A 1$ hypermethylation was estimated using standard statistical methods. The first data on BRCA1 hypermethylation frequency in Bulgarian patients was provided and statistically significant correlations were found.

\section{Patients and Methods}

A group of 135 Bulgarian female patients with sporadic invasive primary breast carcinoma was included in the study. Patients were treated at the Thoracic Clinic of the Bulgarian National Oncological Centre Hospital, Sofia between 2000 and 2003. Staging was done according to the TNM classification of Union International Contre le Cancer (UICC). The average age of the patients was $54.11 \mathrm{yrs}$, standard deviation (SD) \pm 11.5 yrs. Five patients had highly differentiated tumors (G1), 97 - moderately differentiated (G2) and 33 - poorly differentiated (G3). Eightyfive patients had negative nodal status and 50 - positive. Ductal type of carcinoma was found in 122 of the patients and lobular - in 13. Fifty-nine patients were ER-negative, 76 - ER-positive. PR-negative were 58 patients, PR-positive - 77. Adjuvant therapy was applied according to accepted practice guidelines at that time. Patients were followed for a five-year period. All patients were $B R C A 1$ mutation negative as confirmed by previous PCR-SSCP analysis (17). Written consent was taken from all participants in the study. Clinical information was obtained from the existing medical records and is presented in a way preventing patients' identification.

DNA isolation. Tumor DNA was isolated from fresh frozen breast tumor tissue by a standard Proteinase K/Phenol procedure including tissue homogenization in lysis buffer $(10 \mathrm{mM}$ Tris/HCl pH 8.3, $400 \mathrm{mM} \mathrm{NaCl}, 2 \mathrm{mM}$ EDTA-Na, $0.14 \mathrm{mg} / \mathrm{ml}$ Proteinase K, $1 \% \mathrm{SDS}$ ) at $37^{\circ} \mathrm{C}$ for $48 \mathrm{~h}$, phenol/chloroform/ isoamyl alcohol purification and ethanol precipitation. DNA concentration and purity was determined using BioSpec-nano Spectrophotometer (Shimadzu Biotech).

Methylation specific PCR (MSP). The methylation status was determined by MSP of sodium bisulfite-converted DNA. To convert DNA, EZ DNA Methylation KitTM was used following the manufacturer's recommendations (Zymo Research Corporation). One $\mu \mathrm{g}$ of DNA of each sample was subjected to conversion. The obtained pure modified DNA was further PCR analyzed using primers that distinguish methylated (M) and unmethylated (U) DNA. Primer sequences were as follows: $\mathrm{U}$ forward, ggt taa $\mathrm{ttt}$ aga gtt $\mathrm{ttg}$ aga gat $\mathrm{g}$; $\mathrm{U}$ reverse, $\mathrm{t}$ caa caa act cac acc aca caa tca; $M$ forward, ggt taa ttt aga gtt tcg aga gac $\mathrm{g}$; and $\mathrm{M}$ reverse, tca acg aac tca cgc cgc gca atc g (18). Both $\mathrm{U}$ and $\mathrm{M}$ primers amplify a $182 \mathrm{bp}$ product. All amplifications used a hot-start Taq- Polymerase mix (HotStarTaq DNA Polymerase, QIAGEN) and were performed in a total volume of $20 \mu \mathrm{l}$ containing $20 \mathrm{pmol}$ of each primer and $100 \mathrm{ng}$ of modified template DNA. The PCR cycling parameters were as follows: for M primers $-94^{\circ} \mathrm{C}$ for $10 \mathrm{~min} ; 40$ cycles of $94^{\circ} \mathrm{C}$ for $15 \mathrm{~s}, 65^{\circ} \mathrm{C}$ for $30 \mathrm{~s}$, and $72^{\circ} \mathrm{C}$ for $30 \mathrm{~s}$ (final extension for $7 \mathrm{~min}$ ) and for $\mathrm{U}$ primers $-94^{\circ} \mathrm{C}$ for $10 \mathrm{~min} ; 35$ cycles of $94^{\circ} \mathrm{C}$ for $15 \mathrm{~s}, 61^{\circ} \mathrm{C}$ for $30 \mathrm{~s}$, and $72^{\circ} \mathrm{C}$ for $30 \mathrm{~s}$ (final extension for $7 \mathrm{~min}$ ). PCR products were electrophoresed on a $2 \%$ agarose gel in $1 \mathrm{xTBE}$, stained with ethidium bromide, and visualized under UV illumination. We included in each assay both methylated and unmethylated DNA as controls to avoid misinterpretation of the results.

Statistical analysis. The relationship between $B R C A 1$ methylation status and clinico-pathological characteristics of the patients was evaluated using Fisher's exact test and the Chi-squared test. Overall survival (OS) was estimated by the Kaplan-Meier method, and differences between survival curves were assessed for statistical significance using the logrank test. Cox proportional hazards regression model was used to calculate the hazard ratios (HR) and their $95 \%$ confidence intervals $(95 \% \mathrm{CI})$ for each variable in the univariate and multivariate analyses. All $P$-values were two-sided, and results were considered statistically significant at $P$ less than 


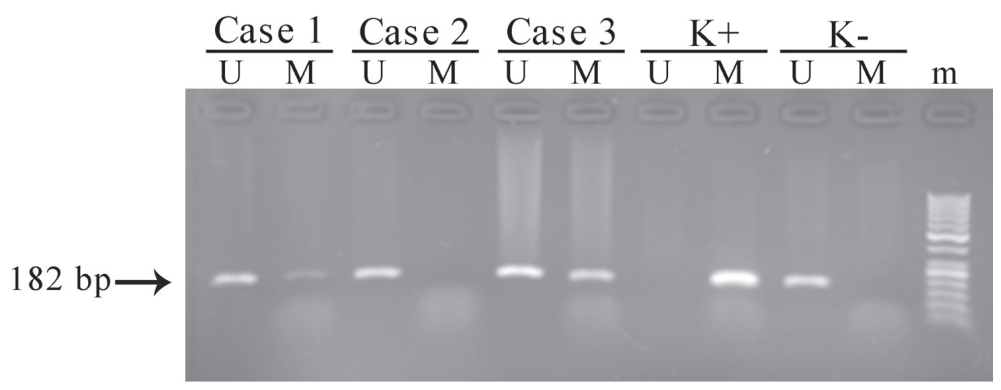

Figure 1. MSP-analysis of $B R C A 1$ in patients with sporadic breast cancer. $2 \%$-agarose gel-electrophoresis of PCR products obtained with primers for unmethylated (U) and methylated (M) DNA; Case 1 and Case 3 - patients with methylated $B R C A 1$ and Case 2 - patient with unmethylated $B R C A 1$; $\mathrm{K}+$ is totally methylated positive control; $\mathrm{K}$ - is unmethylated negative control; $\mathrm{m}-\mathbf{5 0}$ bp marker

0.05. Analyses were done with the SPSS software package (SPSS Inc., Chicago, IL, USA).

\section{Results}

$B R C A 1$ promoter hypermethylation in primary breast carcinomas. Correlation with clinico-pathological and molecular characteristics. We evaluated the level of methylation in the promoter region of $B R C A 1$ in the studied group of patients with breast cancer. Methylation status was analyzed using meth- ylation specific PCR. Hypermethylation was found in $17.04 \%$ of the cases (23/135) (Fig. 1). For a positive control, a totally methylated in vitro DNA (Zymo Research) was included in each amplification reaction. DNA isolated from blood samples of healthy persons was used as a negative control.

To analyze the clinical impact of $B R C A 1$ hypermethylation we compared the methylation status with standard prognostic factors including age of diagnosis, tumor size $(\mathrm{T})$, nodal $(\mathrm{N})$ status, grade of malignancy $(\mathrm{G})$, histological type, and estrogen (ER) and progesterone receptor (PR) status (Table 1). We found

Table 1. $B R C A 1$ methylation and clinico-pathological variables of breast carcinoma

\begin{tabular}{|c|c|c|c|c|c|}
\hline Variable & & $\begin{array}{c}\text { Total cases } \\
n=135\end{array}$ & $\begin{array}{c}\text { Methylated } \\
n=23\end{array}$ & $\begin{array}{c}\text { Non-methylated } \\
\mathrm{n}=112\end{array}$ & $P$ \\
\hline \multirow{4}{*}{ Age } & Years $($ mean $\pm S D)$ & $54.11 \pm 11.5$ & $50.57 \pm 9.5$ & $54.84 \pm 11.8$ & \multirow{4}{*}{0.156} \\
\hline & Range & $29-88$ & $32-69$ & $29-88$ & \\
\hline & $<50$ & 51 & 12 & 39 & \\
\hline & $>/=50$ & 84 & 11 & 73 & \\
\hline \multirow{2}{*}{ Tumor size } & $\mathrm{T} 1$ & 63 & 15 & 48 & \multirow{2}{*}{0.0664} \\
\hline & $\mathrm{T} 2-\mathrm{T} 4$ & 72 & 8 & 64 & \\
\hline \multirow{2}{*}{ N status } & N0 & 85 & 13 & 72 & \multirow{2}{*}{0.487} \\
\hline & $\mathrm{N}+$ & 50 & 10 & 40 & \\
\hline \multirow{3}{*}{ Grade } & G1 & 5 & 0 & 5 & \multirow{3}{*}{0.832} \\
\hline & G2 & 97 & 17 & 80 & \\
\hline & G3 & 33 & 6 & 27 & \\
\hline \multirow{2}{*}{ Histological type } & Lobular & 13 & 5 & 8 & \multirow{2}{*}{0.0464} \\
\hline & Ductal & 122 & 18 & 104 & \\
\hline \multirow{2}{*}{ ER expression } & Positive & 76 & 12 & 64 & \multirow{2}{*}{0.818} \\
\hline & Negative & 59 & 11 & 48 & \\
\hline \multirow{2}{*}{ PgR expression } & Positive & 77 & 12 & 65 & \multirow{2}{*}{0.648} \\
\hline & Negative & 58 & 11 & 47 & \\
\hline \multirow{2}{*}{ p53 mutation } & Positive & 16 & 0 & 16 & \multirow{2}{*}{0.073} \\
\hline & Negative & 119 & 23 & 96 & \\
\hline \multirow{2}{*}{ ATM mutation } & Positive & 11 & 0 & 11 & \multirow{2}{*}{0.210} \\
\hline & Negative & 124 & 23 & 101 & \\
\hline \multirow{2}{*}{ PIK3CA mutation } & Positive & 43 & 5 & 38 & \multirow{2}{*}{0.329} \\
\hline & Negative & 92 & 18 & 74 & \\
\hline \multirow{3}{*}{ HER2 overexpression } & Positive & 19 & 3 & 16 & \multirow{3}{*}{0.367} \\
\hline & Negative & 51 & 14 & 37 & \\
\hline & Unknown & 65 & 6 & 59 & \\
\hline
\end{tabular}




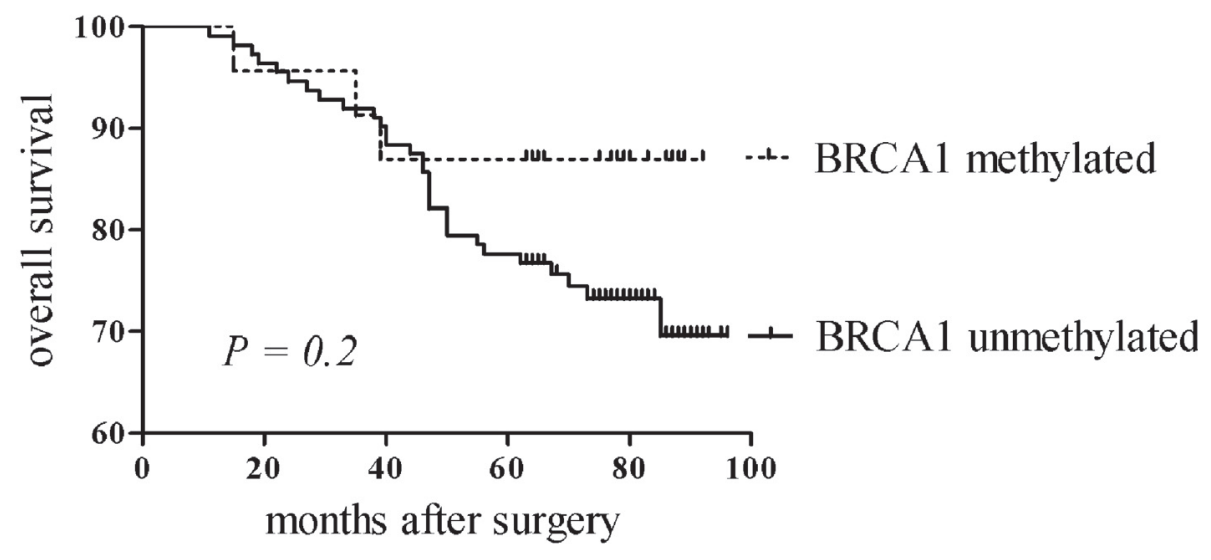

Figure 2. Kaplan-Meier survival curves. OS rates of patients with unmethylated and methylated $B R C A 1$ promoters.

that the disease had a four-year earlier manifest in patients with hypermethylation compared to patients with non-methylated tumors. Lobular carcinomas were significantly more frequent in patients with hypermethylation compared to patients with normally methylated tumors $(P=0.046)$. Tumors with abnormal BRCA1 methylation tended to be smaller in size, predominantly at $\mathrm{T} 1(P=0.066)$.

BRCA1 methylation status was further correlated with several tumor molecular characteristics found previously (17), including mutations in breast cancer related genes such as $p 53$, $A T M$ and PIK3CA genes, and overexpression of HER 2 protein (Table 1). Interestingly, we found that all hypermethylated tumors were $p 53$ negative $(P=0.073)$.

$B R C A 1$ hypermethylation and overall survival. The overall survival (OS) of the studied group of patients with $\mathrm{BC}$ was estimated as a five-year survival rate, as with $\mathrm{BC}$ it is considered that those who had survived the five-year period are quite likely to be cured of the disease. The OS in the studied group was estimated to $75.55 \%(103 / 135)$. Kaplan-Meier analysis showed that patients with hypermethylation in BRCA1 had a better survival rate compared to patients with normally methylated $B R C A 1$ promoter though this finding did not reach statistical significance $(P=0.2)$ (Fig.2).

Univariate and multivariate Cox proportional hazards model was used to estimate the hazard ratio for carriers of BRCA1 hypermethylation compared to non-carriers (Table 2). The analysis included traditional prognostic factors such as age of diagnosis, tumor size, nodal status, grade of malignancy, estrogen and progesterone receptor status, as well as the mutational status of $p 53$, PIK3CA and ATM genes, and the expression profile of $H E R 2$ proto-oncogene. Univariate analysis indicated a protective effect of BRCA1 hypermethylation with a HR of 0.47 though not statistically significant (95\% CI 0.14-1.54, $P=0.213$ ). Similar was the influence of PIK3CA mutations (HR of $0.52,95 \%$ CI $0.22-1.19, P=0.124$ ) and PR status (HR of $0.49,95 \%$ CI $0.24-0.97, P=0.042$ ). The opposite effect had $p 53$ mutations and tumor size. Patients with $p 53$ mutations had 2.29-fold increased risk of dying from breast cancer (95\% CI 0.99-5.27, $P=0.052$ ), and those with T1 tumors -1.93 -fold $(95 \%$ CI $0.94-3.99, P=0.074)$. The only

Table 2. Univariate and multivariate survival analysis

\begin{tabular}{|c|c|c|c|c|c|c|}
\hline \multirow{2}{*}{ Factor } & \multicolumn{3}{|c|}{ Univariate } & \multicolumn{3}{|c|}{ Multivariate } \\
\hline & HR & $95 \% \mathrm{CI}$ & $P$ & HR & $95 \% \mathrm{CI}$ & $P$ \\
\hline BRCA1, methylated vs. unmethylated & 0.47 & $0.14-1.54$ & 0.213 & 0.91 & $0.24-3.41$ & 0.891 \\
\hline p53, mutated vs. wild type & 2.29 & $0.99-5.27$ & 0.052 & 1.04 & $0.34-3.15$ & 0.945 \\
\hline PIK3CA, mutated vs. wild type & 0.52 & $0.22-1.19$ & 0.124 & 0.48 & $0.17-1.34$ & 0.160 \\
\hline ATM, mutated vs. wild type & 1.07 & $0.33-3.51$ & 0.912 & 1.71 & $0.35-8.41$ & 0.508 \\
\hline HER2, overexpressed vs. normal & 1.16 & $0.43-3.12$ & 0.775 & 0.86 & $0.26-2.89$ & 0.810 \\
\hline Age, $<50$ vs. $>=50$ years & 0.99 & $0.97-1.02$ & 0.707 & 0.98 & $0.95-1.02$ & 0.400 \\
\hline G, G1 vs. G2 vs. G3 & 1.38 & $0.69-2.74$ & 0.357 & 1.43 & $0.55-3.72$ & 0.459 \\
\hline T, T1 vs. T2-T4 & 1.93 & 0.94-3.99 & 0.074 & 4.51 & $1.43-14.17$ & 0.010 \\
\hline $\mathrm{N}$, positive vs. negative & 0.91 & $0.45-1.86$ & 0.799 & 0.86 & $0.33-2.28$ & 0.766 \\
\hline ER, positive vs. negative & 1.28 & $0.64-2.57$ & 0.493 & 0.86 & $0.33-2.26$ & 0.764 \\
\hline $\mathrm{PR}$, positive vs. negative & 0.49 & $0.24-0.97$ & 0.042 & 0.5 & $0.21-1.23$ & 0.133 \\
\hline
\end{tabular}

Abbreviations: $\mathrm{HR}$, hazard ratio; $\mathrm{CI}$, confidence interval; $\mathrm{G}$, grade of malignancy; $\mathrm{T}$, tumor size; $\mathrm{N}$, nodal status; $\mathrm{ER}$, estrogen receptor; $\mathrm{PR}$, progesterone receptor Significant $P$ values are in bold 
independent prognostic factor, as shown by the multivariate analysis, that contributed significantly to a decrease in OS was tumor size with a fourfold increased risk of death $(\mathrm{HR}=4.51$, 95\% CI 1.43-14.17, $P=0.010$ ).

\section{Discussion}

Ever since BRCA1 hypermethylation was proved to be involved in sporadic breast carcinoma (13), several studies were dedicated to explore its frequency and correlation with disease characteristics in order to identify a subset of sporadic breast cancers with a specific molecular and clinicopathological phenotype. However, the efforts so far failed to outline such a phenotype, as the available data are rather too heterogeneous and contradictory. Heterogeneity is observed both with respect to frequency and clinical correlations. The reported frequency of BRCA1 promoter hypermethylation in sporadic breast carcinomas is in the range of 9 to $59 \%(15,19-29)$. The frequency found here is the first reported in Bulgarian patients with $\mathrm{BC}$ and is a little below the average BRCA1 hypermethylation frequency. Several factors may account for the differences in the frequency of hypermethylation: the applied methodological approaches and scale of studied groups, adjacent normal tissue contamination, partial hypermethylation, population differences due to exposure to specific environmental agents and others.

Though tumors with $B R C A 1$ promoter methylation display various cancer phenotypes, several most frequent features could be outlined. Thus, though not a rule, most studies demonstrated that BRCA1 hypermethylation correlated with lack of estrogen and progesterone receptor expression $(19,20,22,24,25,30)$ and is most frequently present in younger women, below the age of $50(19,24,29)$. As this in some way resembles the familial $B R C A 1$ mutated tumors, it has been suggested that $B R C A 1$ hypermethylated tumors might phenocopy familial $B R C A 1$ tumors (31). The mechanisms underlying the correlation of BRCA1 methylation with estrogen and progesterone receptor expression have not been fully elucidated. However, it is known that estrogens stimulate the expression of BRCA1 (32), while BRCA1 was shown to directly interact with estrogen receptor thus inhibiting the cellular response to estrogens $(33,34)$. Nevertheless, in our study we did not observe any association between $B R C A 1$ hypermethylation and ER/PR status. This is not an exception, as Xu X et al (29) also didn't find a statistically significant correlation with hormone receptor status. Interestingly, Matros et al. (21), found even the reverse association - a high frequency of $B R C A 1$ promoter methylation among ER positive tumors, suggesting a more complex phenotype association. Similar to other authors $(19,24,29)$ we found that abnormal BRCA1 methylation was more common in breast tumors from patients less than 50 years. Besides, the patients with hypermethylation were 4 years younger than patients with non-methylated tumors.

In our study the subset of patients with hypermethylated $B R C A 1$ displayed more favorable clinical status. Thus, we found that BRCA1 hypermethylation most strongly correlated with lobular histological type, in contrast to other authors who found a correlation with ductal $(19,27)$ and medullary and mucinous (15) types. Lobular breast carcinoma is considered to be more favorable histological type with better survival rates of the patients (35). Additional favorable marker was the finding that tumors with hypermethylation tended to be smaller than non-methylated tumors. The larger size of the tumor is proved to be one of the most significant indicators for a poor prognosis. Another favorable characteristic of the hypermethylated tumors was the observation that none of them had a $p 53$ mutation. Mutated p53 was found to significantly correlate with a greater carcinogenic aggressiveness and worse OS of breast cancer patients $(17,36-38)$. Since $p 53$ and $B R C A 1$ are involved in a same cancer pathway, it could be speculated that the inactivation of the pathway does not require inactivation of both genes (inactivation of one gene may be sufficient).

In a recent study, Stefansson O. et al. found that $\mathrm{CpG}$ island hypermethylation of $B R C A 1$ significantly associates with the basal/triple-negative breast cancer (TNBC) (39). In general patients with TNBC are associated with poor prognosis including larger tumor size, younger age, high tumor grade, positive nodal involvement ect. However, this is not contradictory to our findings since TNBC is a subtype of BC, accounting for only $15 \%$ of all breast cancer patients. Furthermore, in their study Stefansson O. et al. defined a subgroup of TNBCs with $B R C A 1$ aberrations and favorable disease outcome.

We found a weak association between $B R C A 1$ hypermethylation and better OS of patients. Similar correlation was registered by Li S et al (27). However, Xu X et al. (29) on the basis of a large population-based study demonstrated decreased survival associated with $B R C A 1$ promoter methylation among women with BC. Similar were the findings of Karray-Chouayekh S et al. (28) and Chen Y et al. (23). The better survival rate found here by the Kaplan-Meier method was supported by a protective, though not statistically significant, effect of $B R C A 1$ hypermethylation as revealed by the univariate Cox proportional hazards model. The observed better OS of patients with BRCA1 hypermethylation might be partly explained by the favorable clinical and molecular characteristic of BRCA1-hypermethylated tumors.

In conclusion, these are the first reported data on the involvement of $B R C A 1$ promoter hypermethylation in sporadic $\mathrm{BC}$ pathogenesis in Bulgarian patients. The patients with hypermethylation in BRCA1 exhibited more favorable clinical status as their tumors were smaller; they lacked $p 53$ mutations and were of lobular type. The presence of $B R C A 1$ hypermethylation was weakly associated with better OS. A specific BRCA1-related phenotype can not be thus far outlined as the available data are rather too contradictory and heterogeneous.

Acknowledgements: Authors express their gratitude to Dr. Ivan G Gavrilov, National Oncological Centre Hospital, Sofia, who provided the tumor samples and clinical data of patients. This work was funded by the Bulgarian Ministry of Education and Science, project DO $02.310 / 08$. 


\section{References}

[1] VALERIANOVA Z, VUKOV M, DIMITROVA N editors. Cancer incidence in Bulgaria 2006. Sofia: AVIS-24 Ltd., 2008.

[2] HALL JM, LEE MK, NEWMAN B, MORROW JE, ANDERSON LA et al. Linkage of early-onset familial breast cancer to chromosome 17q21. Science 1990; 250: 1684-1689. http:// dx.doi.org/10.1126/science.2270482

[3] MIKI Y, SWENSEN J, SHATTUCK-EIDENS D, FUTREAL PA, HARSHMAN $\mathrm{K}$ et al. A strong candidate for the breast and ovarian cancer susceptibility gene BRCA1. Science 1994; 266: 66-71. http://dx.doi.org/10.1126/science.7545954

[4] DENG CX, WANG RH Roles of BRCA1 in DNA damage repair: a link between development and cancer. Human Molecular Genetics 2003; 12, Review Issue 1: 113-123.

[5] XU B, KIM S, KASTAN MB Involvement of Brcal in S-phase and $\mathrm{G}$ (2)-phase checkpoints after ionizing irradiation. Mol Cell Biol 2001; 21: 3445-3450. http://dx.doi.org/10.1128/ MCB.21.10.3445-3450.2001

[6] HARKIN DP, BEAN JM, MIKLOS D, SONG YH, TRUONG VB et al. Induction of GADD45 and JNK/SAPK dependent apoptosis following inducible expression of BRCA1. Cell 1999; 97: 575-586. http://dx.doi.org/10.1016/S0092-8674(00)80769-2

[7] SHUKLA V, COUMOUL X, LAHUSEN T, WANG RH, XU X et al. BRCA1 affects global DNA methylation through regulation of DNMT1. Cell Res 2010; 20: 1201-1215. http://dx.doi. org/10.1038/cr.2010.128

[8] THOMPSON ME, JENSEN RA, OBERMILLER PS, PAGE DL, HOLT JT Decreased expression of BRCA1 accelerates growth and is often present during sporadic breast cancer progression. Nat Genet 1995; 9: 444-450. http://dx.doi. org/10.1038/ng0495-444

[9] SAKAI T, TOGUCHIDA J, OHTANI N, YANDELL DW, RAPAPORT JM et al. Allele-specific hypermethylation of the retinoblastoma tumor-suppressor gene. Am J Hum Genet 1991; 48: 880- 888.

[10] HERMAN JG, LATIF F, WENG Y, LERMAN MI, ZBAR B et al. Silencing of the VHL tumor-suppressor gene by DNA methylation in renal carcinoma. Proc Natl Acad Sci USA 1994; 91: 9700 - 9704. http://dx.doi.org/10.1073/pnas.91.21.9700

[11] HILTUNEN MO, ALHONEN L, KOISTINAHO J, MYOHANEN S, PAAKKONEN M et al. Hypermethylation of the APC (adenomatous polyposis coli) gene promoter region in human colorectal carcinoma. Int J Cancer 1997; 70: 644 - 648. http://dx.doi.org/10.1002/(SICI)10970215(19970317)70:6<644::AID-IJC3>3.0.CO;2-V

[12] AI L, VO QN, ZUO C, LI L, LING W et al. Ataxia-telangiectasia-mutated (ATM) gene in head and neck squamous cell carcinoma: promoter hypermethylation with clinical correlation in 100 cases. Cancer Epidemiol Biomarkers Prev 2004; 13: 150-156. http://dx.doi.org/10.1158/1055-9965.EPI-082-3

13] DOBROVIC A, SIMPFENDORFER D Methylation of the BRCA1 Gene in Sporadic Breast Cancer. Cancer Res 1997; 57: 3347-3350.

[14] BIANCO T, CHENEVIX-TRENCH G, WALSH DC, COOPER JE, DOBROVIC A Tumour-specific distribution of BRCA1 promoter region methylation supports a pathogenetic role in breast and ovarian cancer. Carcinogenesis 2000; 21: 147-151. http://dx.doi.org/10.1093/carcin/21.2.147

[15] ESTELLER M, SILVA JM, DOMINGUEZ G, BONILLA F, MATIAS-GUIU X et al. Promoter hypermethylation and BRCA1 inactivation in sporadic breast and ovarian tumors. J Natl Cancer Inst 2000; 92: 564-569. http://dx.doi.org/10.1093/ jnci/92.7.564

[16] RICE JC, MASSEY-BROWN KS, FUTSCHER BW Aberrant methylation of the BRCA1 CpG island promoter is associated with decreased BRCA1 mRNA in sporadic breast cancer cells. Oncogene 1998; 17: 1807-1812. http://dx.doi.org/10.1038/ sj.onc. 1202086

[17] BOZHANOV SS, ANGELOVA SG, KRASTEVA ME, MARKOV TL, CHRISTOVA SL et al. Alterations in p53, BRCA1, ATM, PIK3CA, and HER2 genes and their effect in modifying clinicopathological characteristics and overall survival of Bulgarian patients with breast cancer. J Cancer Res Clin Oncol 2010; 136: 1657-1669. http://dx.doi.org/10.1007/s00432-010-0824-9

[18] BALDWIN RL, NEMETH E, TRAN H, SHVARTSMAN H, CASS I et al. BRCA1 promoter region hypermethylation in ovarian carcinoma: a population-based study. Cancer Res 2000; 60: 5329-5333.

[19] BIRGISDOTTIR V, STEFANSSON OA, BODVARSDOTTIR SK, HILMARSDOTTIR H, JONASSON JG et al. Epigenetic silencing and deletion of the BRCA1 gene in sporadic breast cancer. Breast Cancer Res 2006; 8: R38. http://dx.doi. org/10.1186/bcr1522

[20] CATTEAU A, HARRIS WH, XU CF, SOLOMON E Methylation of the BRCA1 promoter region in sporadic breast and ovarian cancer: correlation with disease characteristics. Oncogene 1999; 18: 1957-1965. http://dx.doi.org/10.1038/ sj.onc. 1202509

[21] MATROS E, WANG ZC, LODEIRO G, MIRON A, IGLEHART JD et al. BRCA1 promoter methylation in sporadic breast tumors: relationship to gene expression profiles. Breast Cancer Res Treat 2005; 91: 179-186. http://dx.doi.org/10.1007/ $\underline{\text { s10549-004-7603-8 }}$

[22] BAGADI SA, PRASAD CP, KAUR J, SRIVASTAVA A, PRASHAD R et al. Clinical significance of promoter hypermethylation of RASSF1A, RARbeta2, BRCA1 and HOXA5 in breast cancers of Indian patients. Life Sci 2008; 82: 1288-1292. http://dx.doi.org/10.1016/j.lfs.2008.04.020

[23] CHEN Y, ZHOU J, XU Y, LI Z, WEN X et al. BRCA1 promoter methylation associated with poor survival in Chinese patients with sporadic breast cancer. Cancer Sci 2009; 100: 1663-1667. http://dx.doi.org/10.1111/j.1349-7006.2009.01225.x

[24] WEI M, GRUSHKO TA, DIGNAM J, HAGOS F, NANDA R et al. BRCA1 promoter methylation in sporadic breast cancer is associated with reduced BRCA1 copy number and chromosome 17 aneusomy. Cancer Res 2005; 65: 10692-10699. http://dx.doi.org/10.1158/0008-5472.CAN-05-1277

[25] NIWA Y, OYAMA T, NAKAJIMA T BRCA1 expression status in relation to DNA methylation of the BRCA1 promoter region in sporadic breast cancers. Jpn J Cancer Res 2000; 91: 519-526.

[26] JING F, ZHANG J, TAO J, ZHOU Y, JUN L et al. Hypermethylation of tumor suppressor genes BRCA1, p16 and 14-3-3sigma 
in serum of sporadic breast cancer patients. Onkologie 2007; 30: 14-19. http://dx.doi.org/10.1159/000096892

[27] LI S, RONG M, IACOPETTA B DNA hypermethylation in breast cancer and its association with clinicopathological features. Cancer Lett 2006; 237: 272-280. http://dx.doi. org/10.1016/j.canlet.2005.06.011

[28] KARRAY-CHOUAYEKH S, TRIFA F, KHABIR A, BOUJELBANE N, SELLAMI-BOUDAWARA T et al. Clinical significance of epigenetic inactivation of hMLH1 and BRCA1 in Tunisian patients with invasive breast carcinoma. J Biomed Biotechnol 2009; Vol 2009. http://dx.doi.org/10.1155/2009/ $\underline{369129}$

[29] XU X, GAMMON MD, ZHANG Y, BESTOR TH, ZEISEL $\mathrm{SH}$ et al. BRCA1 promoter methylation is associated with increased mortality among women with breast cancer. Breast Cancer Res Treat 2009; 115: 397-404. http://dx.doi. org/10.1007/s10549-008-0075-5

[30] MIRZA S, SHARMA G, PRASAD CP, PARSHAD R, SRIVASTAVA A et al. Promoter hypermethylation of TMS1, BRCA1, ERalpha and PRB in serum and tumor DNA of invasive ductal breast carcinoma patients. Life Sci 2007; 81: 280-287. http://dx.doi.org/10.1016/j.lfs.2007.05.012

[31] TURNER N, TUTT A, ASHWORTH A Hallmarks of ,BRCAness' in sporadic cancers. Nature Reviews of Cancer 2004; 4: 814-819. http://dx.doi.org/10.1038/nrc1457

[32] HILAKIVI-CLARKE L Estrogens, BRCA1, and breast cancer. Cancer Res 2000; 60: 4993-5001.

[33] FAN S, WANG J, YUAN R, MA Y, MENG Q et al. BRCA1 inhibition of estrogen receptor signaling in transfected cells.
Science 1999; 284: 1354-1356. http://dx.doi.org/10.1126/ science.284.5418.1354

[34] FAN S, MA YX, WANG C, YUAN RQ, MENG Q et al. Role of direct interaction in BRCA1 inhibition of estrogen receptor activity. Oncogene 2001; 20: 77-87. http://dx.doi.org/10.1038/ sj.onc. 1204073

[35] DIAN D, HEROLD H, MYLONAS I, SCHOLZ C, JANNI W et al. Survival analysis between patients with invasive ductal and invasive lobular breast cancer. Arch Gynecol Obstet 2009; 279: 23-28. http://dx.doi.org/10.1007/s00404-008-0662-z

[36] PETITJEAN A, ACHATZ MI, BORRESEN-DALE AL, HAINAUT P, OLIVIER M TP53 mutations in human cancers: functional selection and impact on cancer prognosis and outcomes. Oncogene 2007; 26: 2157-2165. http://dx.doi. org/10.1038/sj.onc.1210302

[37] OLIVIER M, LANGEROD A, CARRIERI P, BERGH J, KLAAR $S$ et al. The clinical value of somatic TP53 gene mutations in 1,794 patients with breast cancer. Clin Cancer Res 2006; 12: 1157-1167. http://dx.doi.org/10.1158/1078-0432.CCR-05-1029

[38] LANGEROD A, ZHAO H, BORGAN O, NESLAND JM, BUKHOLM IR et al. TP53 mutation status and gene expression profiles are powerful prognostic markers of breast cancer. Breast Cancer Res 2007; 9: R30. http://dx.doi.org/10.1186/ bcr1675

[39] STEFANSSON OA, JONASSON JG, OLAFSDOTTIR K, HILMARSDOTTIR H, OLAFSDOTTIR G et al. CpG island hypermethylation of BRCA1 and loss of pRb as co-occurring events in basal/triple-negative breast cancer. Epigenetics 2011; 6:638-649. http://dx.doi.org/10.4161/epi.6.5.15667 